\title{
A Novel Role for Brain Interleukin-6: Facilitation of Cognitive Flexibility in Rat Orbitofrontal Cortex
}

\author{
Jennifer J. Donegan, ${ }^{1}$ Milena Girotti, ${ }^{1}$ Marc S. Weinberg, ${ }^{2}$ and David A. Morilak ${ }^{1}$ \\ ${ }^{1}$ Department of Pharmacology and Center for Biomedical Neuroscience, University of Texas Health Science Center at San Antonio, San Antonio, Texas \\ 78229, and ${ }^{2}$ Gene Therapy Center, University of North Carolina at Chapel Hill, Chapel Hill, North Carolina 27599
}

Cytokines, small proteins released by the immune system to combat infection, are typically studied under inflammatory conditions. However, these molecules are also expressed in the brain in basal, nonpathological states, where they can regulate neuronal processes, such as learning and memory. However, little is known about how cytokine signaling in the brain may influence higher-order cognitive functions. Cognitive flexibility is one such executive process, mediated by the prefrontal cortex, which requires an adaptive modification of learned behaviors in response to environmental change. We explored the role of basal IL-6 signaling in the orbitofrontal cortex (OFC) in reversal learning, a form of cognitive flexibility that can be measured in the rat using the attentional set-shifting test. We found that inhibiting IL-6 or its downstream JAK/STAT signaling pathway in the OFC impaired reversal learning, suggesting that basal IL-6 and JAK/STAT signaling facilitate cognitive flexibility. Further, we demonstrated that elevating IL- 6 in the OFC by adeno-associated virusmediated gene delivery reversed a cognitive deficit induced by chronic stress, thus identifying IL- 6 and the downstream JAK/STAT signaling pathway as potentially novel therapeutic targets for the treatment of stress-related psychiatric diseases associated with cognitive dysfunction.

Key words: interleukin-6; JAK/STAT; cognitive flexibility; depression; orbitofrontal cortex; reversal learning

\section{Introduction}

Cognitive flexibility, the ability to modify previous learning in response to environmental change, is critical for adaptive behavior. Reversal learning is one form of cognitive flexibility, requiring subjects to switch cue-directed operant responding from a previously positive stimulus that is now negative to a previously negative stimulus that is now associated with reward. Reversal learning deficits have been associated with psychiatric diseases, including schizophrenia (Leeson et al., 2009), obsessive-compulsive disorder (Remijnse et al., 2006), and depression (Must et al., 2006). Optimal reversal learning depends on the functional integrity of the orbitofrontal cortex (OFC) and the dorsal striatum (Clarke et al., 2008), and monoaminergic neurotransmitters,

Received Sept. 16, 2013; revised Nov. 7, 2013; accepted Nov. 27, 2013.

Author contributions: J.J.D., M.G., and D.A.M. designed research; J.J.D. and M.G. performed research; M.S.W. contributed unpublished reagents/analytic tools; J.J.D., M.G., and D.A.M. analyzed data; J.J.D., M.G., and D.A.M. wrote the paper.

This work was supported by the Brain and Behavior Research Foundation, NARSAD Van Ameringen Young Investigator Award 18746 to M.G., National Institutes of Mental Health Grants R01MH058531 and R01MH072672 to D.A.M., and National Institute of Neurological Disorders and Stroke Grant F32NS070356 to M.S.W. We thank Ms. Miranda Morgan for her contribution to this work as a participant in the South Texas Advanced Research Training Undergraduate Program (START-UP; Grant R25NS080684, funded by the National Institutes of Health Blueprint Program for Enhancing Neuroscience Diversity through Undergraduate Research Education) and Drs. Thomas McCown and R. Jude Samulski, University of North Carolina Gene Therapy Center, for assistance with viral vector production.

The authors declare no competing financial interests.

Correspondence should be addressed to Dr. David A. Morilak, Department of Pharmacology, Mail Code 7764, University of Texas Health Science Center, 7703 Floyd Curl Drive, San Antonio, TX 78229-3900. E-mail: morilak@uthscsa.edu.

DOI:10.1523/JNEUROSCI.3968-13.2014

Copyright $\odot 2014$ the authors $\quad 0270-6474 / 14 / 340953-10 \$ 15.00 / 0$ including serotonin, can modulate reversal learning (Clarke et al., 2004; Lee et al., 2007; DeSteno and Schmauss, 2009; LapizBluhm et al., 2009). In addition to monoamines and other traditional neurotransmitters, increasing evidence suggests that immune signaling molecules (e.g., cytokines) can also modulate synaptic plasticity and cognition in the brain. The pleiotropic cytokine, interleukin-6 (IL-6), which has both proinflammatory and anti-inflammatory actions, also plays a complex role in regulating cognitive function (Yirmiya and Goshen, 2011). A growing literature suggests that stress can increase cytokine levels (Steptoe et al., 2007; Jankord et al., 2010) and that excessive IL-6 signaling induced by aging or inflammation may impair cognitive processes, such as spatial learning and memory (Sparkman et al., 2006; Dugan et al., 2009). In humans, elevated IL-6 has been correlated with age-related cognitive decline (Weaver et al., 2002), and plasma IL-6 strongly predicts the cognitive symptoms of depression (Gimeno et al., 2009).

Based on these observations, we set out to determine whether IL-6 signaling can modulate reversal learning, with the a priori hypothesis that IL-6 may contribute to a selective reversal learning deficit induced by chronic cold stress (Lapiz-Bluhm et al., 2009). However, in the first experiment, we found that blocking IL-6 actually impaired reversal learning in both stressed and nonstressed animals, suggesting that basal IL- 6 signaling in the brain (i.e., in the absence of stress or inflammation) may instead facilitate cognitive function. Indeed, results of other studies have shown that IL-6 is not universally detrimental for cognition (Yirmiya and Goshen, 2011). For example, in young, healthy animals, exogenous IL-6 administration has no effect (Oitzl et al., 1993), and genetic IL-6 knock-out actually impairs performance 
on spatial learning tasks (Braida et al., 2004). Further, in animals compromised by treatment with scopolamine or ischemia, IL-6 improved memory function (Matsuda et al., 1996; Braida et al., 2004). Thus, in subsequent experiments, we explored the role of basal IL-6 signaling in modulating reversal learning. We first localized the effect of IL- 6 to the OFC and demonstrated that, under basal conditions, IL-6 is expressed primarily by neurons in the OFC. We then tested the JAK/STAT signaling pathway as a potential mechanism by which IL-6 facilitates reversal learning. Finally, because endogenous IL- 6 facilitates reversal learning, we then tested the hypothesis that chronic overexpression of IL- 6 , or acute microinjection of exogenous IL-6 into the OFC, would attenuate a reversal learning deficit caused by chronic stress.

\section{Materials and Methods}

Animals. A total of 147 adult male Sprague Dawley rats (Harlan, $220-240 \mathrm{~g}$ ) were maintained on a $12 \mathrm{~h} / 12 \mathrm{~h}$ light/dark cycle, with food and water available ad libitum. All procedures were consistent with National Institutes of Health guidelines (National Institutes of Health publications no. 80-23, revised 1978) and approved by the Institutional Animal Care and Use Committee of the University of Texas Health Science Center at San Antonio.

Chronic intermittent cold (CIC) stress. Rats were moved in their home cage into a $4^{\circ} \mathrm{C}$ cold room for $6 \mathrm{~h}$ per day for 14 consecutive days. Controls remained in housing for the same period of time.

Stereotaxic surgeries. Guide cannulae or injectors were inserted stereotaxically, targeting the OFC (from bregma: $\mathrm{AP} 2.9, \mathrm{ML} \pm 2.6, \mathrm{DV}-5.2$ ), dorsal striatum (AP 1.2, ML $\pm 2.8, \mathrm{DV}-5.0$ ), or lateral ventricles (AP $-0.9, \mathrm{ML} \pm 1.4, \mathrm{DV}-4.5$; Paxinos and Watson, 2006). After surgery, animals recovered for at least $5 \mathrm{~d}$ before any experimental procedures. Cannula placement was confirmed histologically for all animals.

Adeno-associated virus (AAV) production. To generate a constitutively secreted, functional IL- 6 construct, the IL-1 receptor antagonist signal peptide sequence was fused to the $5^{\prime}$ end of the IL-6 mature peptide sequence, based on previous work (Wingren et al., 1996). Nested PCR was performed as follows: First, the human IL- 6 mature peptide sequence was amplified for 20 cycles using a forward primer containing the 3' portion of the human IL-1 receptor antagonist signal peptide immediately adjacent to and in frame with the $5^{\prime}$ portion of human IL- 6 mature peptide sequence: tcctcttcctgttccattcagagacgatctgc ${ }^{\star}$ gccccagtacccccagg, where ${ }^{\star}$ represents the location of the linked sequences; a reverse primer for the human IL-6 mature peptide: actagcggccgcgatatcctacattt, containing an EcoR1 restriction site; and a template human IL-6 coding sequence cassette (NCBI accession: BC015511, Thermo Scientific clone ID: MHS6278-202756684). A second PCR amplification was performed for 30 cycles using the purified first amplification product and the forward primer: accggtgccaccatcagtaaccggtgccaccatggaaatctgcagaggectccgcagtca cctaatcactctcctcctcttcctgttcc, containing an Agel restriction site followed by a Kozak sequence and the $5^{\prime}$ coding sequence of human IL-1 receptor antagonist signal peptide. The sequence-verified PCR product was digested with EcoR1 and Age1 enzymes and subcloned into an AAV terminal repeat-containing cassette, behind a hybrid chicken $\beta$ actin promoter (Gray et al., 2011). Virus was produced in HEK-293 cells as previously described (Grieger et al., 2006; Johnson et al., 2010). Briefly, polyethylenimine (linear molecular weight, $\sim 25,000$ ) was used for triple transfection of the pXR2/pXR5 rep and cap plasmid, the pXX6-80 helper plasmid, and the IL- 6 fusion product or the control GFP expression cassette flanked by inverted terminal repeats. At $72 \mathrm{~h}$ after transfection, cells were harvested and virus was purified by dual cesium chloride density gradient centrifugation. Peak fractions of AAV were dialyzed into $1 \times$ PBS and 5\% sorbitol. Titers were calculated by quantitative PCR according to established procedures (Johnson et al., 2010) using a LightCycler 480 using TaqMan PCRmix (Applied Biosystems) and primers designed against the SV40 polyA sequence: (forward) 5'-AGCAATAGCATCACAAATTTCACAA-3', and (reverse) 5'-CCAGACATGATAAGATACATTGATGAGTT-3', along with a dual-labeled probe: 5'-fam AGCATTTTTTTCACTGCATTCTAGTTGTGGTTTGTC-3' -tamra (Integrated DNA Technologies).
Attentional set-shifting test. The attentional set-shifting test (AST) was performed as described previously (Danet et al., 2010; Furr et al., 2012). Briefly, $7 \mathrm{~d}$ before testing, rats were restricted to $14 \mathrm{~g}$ food/d, with ad libitum access to water. Rats were trained to dig in terracotta pots to receive a $1 / 4$ Honey Nut Cheerio reward. The pots were defined by cues along two stimulus dimensions: the digging medium filling the pot and an odor applied to the inner rim of the pot. During testing, the "positive" pot was baited with reward buried within the digging medium. Each stage of testing required a different discrimination, with a criterion of six consecutive correct trials required to proceed to the next stage. The first stage was a simple discrimination, with only one stimulus dimension (odor or medium) present. The second stage was a compound discrimination in which the same discrimination was required and the second irrelevant dimension was introduced as a distractor. The third stage was the reversal learning task. The same odors and media were used, and the relevant dimension (odor or medium) remained the same, but the negative cue from the previous stage was now positive, and the positive cue from the previous stage was now negative. The dependent measure was the number of trials to criterion on the reversal learning stage. Animals that did not dig within $10 \mathrm{~min}$ on six consecutive trials or that did not meet criterion within 50 trials on any test stage were excluded from analysis.

Tissue collection. For the OFC, a $2 \mathrm{~mm}$ coronal section was cut from 2 to $4 \mathrm{~mm}$ caudal to the frontal pole. From this coronal slab, a wedge of tissue was dissected from the lateral margin of the brain to the medial boundary of the forceps minor, ventral to the forceps minor and dorsal to the rhinal sulcus.

ELISA. Total homogenates were prepared in Invitrogen Tissue Extraction Reagent I with protease and phosphatase inhibitors (Sigma) and used to measure rat and human IL-6 by ELISA (Invitrogen) according to the manufacturer's instructions. IL-6 levels were normalized to total protein, as determined by the Bradford assay.

Western blot. Tissue homogenates were prepared as above, and equal amounts of protein were subjected to SDS-PAGE and transferred to PVDF membrane (Immobilon P, Millipore). The following primary antibodies (Cell Signaling Technology) were used: phospho-STAT3 (Tyr 705; 1:1000), phospho-ERK1/2 (Thr202/Tyr204; 1:10,000), phosphoAKT (Ser473; 1:5000), and phospho-AKT (Thr308; 1:3000). After incubation with an HRP-linked secondary antibody (Cell Signaling Technology) and Prime ECL detection reagent (GE Healthcare), blots were stripped and reprobed with a STAT3 antibody (Santa Cruz Biotechnology, sc-8019; 1:1000), ERK1/2 antibody (Santa Cruz Biotechnology, sc-94; 1:50,000), or AKT antibody (Cell Signaling Technology; 1:80,000), which were used to normalize the corresponding phospho-protein signals.

Immunohistochemistry. Rats were anesthetized and perfused transcardially with $4 \%$ paraformaldehyde. Dual-label fluorescence immunohistochemistry was performed sequentially on free-floating $40 \mu \mathrm{m}$ sections through the OFC. For antigen retrieval and peroxide quenching, sections were boiled in $10 \mathrm{~mm}$ citric acid, $\mathrm{pH}$ 6. The following primary antibodies were used: GFAP (Cell Signaling Technology, 1:500), CD11b (AbD Serotec, 1:500), Iba1 (Millipore, 1:5000), NeuN (Millipore, 1:500), IL-6 (Santa Cruz Biotechnology, M19, 1:250), GFP (Millipore, 1:15,000), or phospho-STAT3 (1:100,Cell Signaling Technology). After incubation with biotinylated secondary antibodies (GE Healthcare, Sigma), sections were incubated with an avidinperoxidase conjugate (Vectastain $\mathrm{ABC}$, Vector Laboratories) and then Tyramide Signal Amplification Cy3 reagent for the cell markers, and fluorescein reagent for IL- 6 and phospho-STAT3 (PerkinElmer). Sections were mounted on gelatin-coated slides, coverslipped with Vectashield mounting media (Vector Laboratories), and then imaged using an Olympus IX81 Motorized Inverted microscope. Digital images were acquired using FV10-ASW software and enhanced using ImageJ.

Statistics. Animals were randomly assigned to treatment groups. In all figures, data are shown as mean \pm SEM and $n$ is indicated in the figure legend. For Experiment 2, trials to meet criterion (TTC) on the reversal learning stage of the AST were analyzed using Student's $t$ test. For all other experiments, TTC, IL-6 protein levels, phospho-STAT3, phosphoERK1/2, and phospho-AKT levels were analyzed by two-way ANOVA. 
The Bonferroni post hoc test was used when interactions or main effects were significant. All tests were two-tailed, and significance was determined at $p<0.05$.

Experiment 1: effect of chronic immunoneutralization of brain IL-6 on reversal learning. To test the hypothesis that IL- 6 contributes to the deficit in reversal learning induced by CIC stress, we administered a neutralizing polyclonal goat anti-rat IL-6 antibody or normal goat IgG (R\&D Systems) as control to CIC-stressed or unstressed control animals. Intracerebroventricular antibody administration has been shown to penetrate the brain parenchyma and affect behavior (Balschun et al., 2004; Palin et al., 2009). Therefore, osmotic minipumps (Alzet model 1004; flow rate $2.64 \mu \mathrm{l} / \mathrm{d}$ ), filled with anti-IL-6 antibody or normal goat IgG, diluted in saline to a concentration calculated to deliver $400 \mathrm{ng} / \mathrm{d}$, were implanted subcutaneously. This dose has been shown to effectively block LPSinduced changes in neuronal function (Palin et al., 2009). Dual-injection cannulae (Plastics One), connected to the minipumps by plastic tubing, were implanted into the lateral ventricles. After $5 \mathrm{~d}$ recovery, animals were randomly assigned to CIC stress or nonstress control groups. Three days after the end of stress, or at the equivalent time point for controls, rats were tested on the AST. After completion of the test, the OFC was collected and STAT3, ERK1/2, and AKT phosphorylation was measured by Western blot.

Experiment 2: effect of acute IL-6 immunoneutralization in OFC on reversal learning. To identify the brain region responsible for the detrimental effect of chronic IL-6 neutralization on reversal learning seen in Experiment 1, rats were implanted with bilateral guide cannulae (22gauge stainless-steel, $11 \mathrm{~mm}$ length) with their tips $1 \mathrm{~mm}$ above either the OFC or dorsal striatum. After 2 weeks recovery, rats were tested on the AST. Upon completion of the compound discrimination task, obdurators were removed and microinjectors (30-gauge stainless steel) were inserted, extending $1 \mathrm{~mm}$ beyond the cannula tips. Microinjectors were connected by a fluid-filled line to a Hamilton syringe mounted on a syringe pump (Instech Laboratories). IL-6 antibody or control IgG was injected bilaterally ( $50 \mathrm{ng} / 0.5 \mu \mathrm{l}$ saline vehicle in OFC, $100 \mathrm{ng} / 1.0 \mu \mathrm{l}$ in dorsal striatum) at a rate of $0.25 \mu \mathrm{l} / \mathrm{min}$. The concentration of antibody was similar to that used in Experiment 1, the assumption being that if this concentration was effective with intracerebroventricular delivery, it should also be effective delivered directly into the OFC or dorsal striatum. Injectors remained in place 3 min to allow for diffusion before removing. Five minutes after injection, testing resumed with the reversal learning task. Polyclonal goat IgG injected intravenously takes $63 \mathrm{~h}$ to degrade by half, suggesting that the antibody was active throughout the reversal learning test (Peppard and Orlans, 1980).

Experiment 3: effect of chronic IL-6 overexpression in the OFC on the CIC stress-induced reversal learning deficit. To determine whether elevating IL-6 in the OFC attenuates the reversal learning deficit caused by CIC stress, an AAV was used to overexpress either human IL-6 (AAV-IL-6) or green fluorescent protein (AAV-GFP), as a control. The pseudotyped AAV2/5 (AAV2 vector within AAV5 capsid) has been shown to exclusively infect neurons throughout the brain, producing stable gene expression (Burger et al., 2004). Rats were anesthetized and placed in a stereotaxic frame. Microinjectors were lowered into the OFC. AAV-IL-6 or AAV-GFP $\left(6.9 \times 10^{7}\right.$ viral genomes/ $\left.\mu \mathrm{l}\right)$ was injected in $0.5 \mu \mathrm{l}$ saline per side, at a rate of $0.25 \mu \mathrm{l} / \mathrm{min}$. This viral dose was chosen based on pilot studies demonstrating a threefold to fourfold increase in IL-6 expression and activation of downstream signaling pathways, without approaching levels seen under inflammatory conditions (Harting et al., 2008). Injectors were left in place for $3 \mathrm{~min}$ to allow diffusion. After $5 \mathrm{~d}$ recovery, animals were exposed to CIC stress for 2 weeks, then tested on the AST. Upon completion of the test, the OFC was collected for rat and human IL-6 analysis by ELISA, and for measurement of STAT3, ERK1/2, and AKT phosphorylation by Western blot. Additional animals were used for immunohistochemistry to define the spread of infection and identify the cell types infected.

Experiment 4: effect of acute IL-6 administration into the OFC on the CIC stress-induced reversal learning deficit. To determine whether elevated IL- 6 is required throughout the CIC stress treatment or whether increasing IL-6 in the OFC acutely at the time of testing is sufficient to attenuate the stress-induced deficit in cognitive function, rats were im- planted with bilateral guide cannulae aimed at the OFC. After recovery, animals were exposed to CIC stress, then tested on the AST. Immediately before the reversal learning stage of the test, $1.0 \mathrm{ng} / 0.5 \mu \mathrm{l}$ of recombinant rat IL-6 (R\&D Systems) or $0.5 \mu \mathrm{l}$ saline vehicle was injected bilaterally into the OFC. This dose was chosen based on pilot tests using doses from 0.01 to $1.0 \mathrm{ng}$.

Experiment 5: effect of acute JAK2/STAT3 inhibition in the OFC on reversal learning. To determine whether acute inhibition of endogenous basal JAK2/STAT3 signaling can influence reversal learning, rats were implanted with bilateral guide cannulae aimed at the OFC. Animals were allowed at least 2 weeks recovery, then tested on the AST. After completion of the compound discrimination, rats received bilateral microinjections into the OFC of vehicle ( $0.38 \% \mathrm{EtOH}$ in saline), $37.5 \mu \mathrm{M}$ (9.6 ng) or $75 \mu \mathrm{M}(19.3 \mathrm{ng})$ JSI-124, a JAK/STAT inhibitor with an in vitro $\mathrm{IC}_{50}$ value between 0.8 and $7.5 \mu \mathrm{M}$ (Sun et al., 2005). Five minutes after injections, testing resumed with the reversal learning task.

Experiment 6: cellular localization of IL-6 and JAK/STAT expression in the OFC. To identify the cell types that express IL- 6 under basal conditions, naive rats were perfused for dual-fluorescence immunohistochemistry to label IL-6 and either NeuN for neurons, GFAP for astrocytes, or CD11b for microglia. To identify the cell types that demonstrated JAK/ STAT activation after IL-6 overexpression, the AAV-IL- 6 virus was injected into the OFC to increase IL- 6 expression. Rats were allowed 3 weeks to recover, then perfused for dual-fluorescence immunohistochemistry to colocalize phospho-STAT3 expression with the cell markers above. To quantify the number of cells expressing each label, two sections through the OFC were imaged from each rat. For each section, the OFC was defined as a triangular area with its vertices at the rhinal sulcus, the medial boundary of the forceps minor, and lateral edge of the forceps minor. A standard field of view $\left(200 \mu \mathrm{m}^{2}\right)$ was positioned within the center of this area. The total number of cells labeled by each marker were counted within this field, and the percentages exhibiting coexpression were calculated.

\section{Results}

\section{Experiment 1: chronic immunoneutralization of brain IL-6 impairs reversal learning}

To determine whether IL-6 signaling in the brain influences reversal learning, chronic intracerebroventricular infusion of a neutralizing anti-IL-6 antibody or an IgG control antibody was administered to unstressed control animals or to rats subjected to CIC stress treatment, which we have shown previously to produce a deficit in reversal learning (Danet et al., 2010). Three days after the termination of CIC stress, reversal learning was assessed using the AST. Our initial hypothesis was that the anti-IL-6 antibody would prevent the reversal learning deficit caused by chronic cold stress. However, the results instead showed that IL-6 neutralization impaired reversal learning in both stressed and nonstressed animals. There were significant main effects of both CIC stress and anti-IL-6 antibody administration on the dependent measure of TTC for successful reversal learning on the AST (Fig. 1 $a$; two-way ANOVA, main effect of stress: $F_{(1,34)}=4.222$, $p=0.0476$; antibody treatment: $\left.F_{(1,34)}=10.48, p=0.0027\right)$. Neither stress nor the anti-IL-6 antibody affected TTC during training or on the simple and compound discrimination test stages preceding the reversal task (data not shown), suggesting that there were no nonspecific effects on motivation, learning of the reward contingencies, or ability to perform the task. To confirm the effectiveness of antibody treatment and to identify potential signaling pathways involved in this behavioral effect, we also measured phosphorylation of STAT3, ERK1/2, and AKT in the OFC of the same rats. We found that IL- 6 neutralization reduced STAT3 and ERK1/2 activity without affecting AKT. Specifically, although there was no effect of CIC stress, there was a significant main effect of antibody treatment on STAT3 phosphorylation (Fig. $\left.1 b ; F_{(1,30)}=8.971, p=0.0055\right)$ and ERK1/2 
a

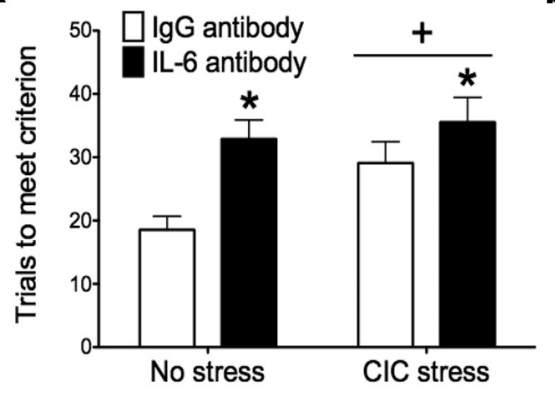

d

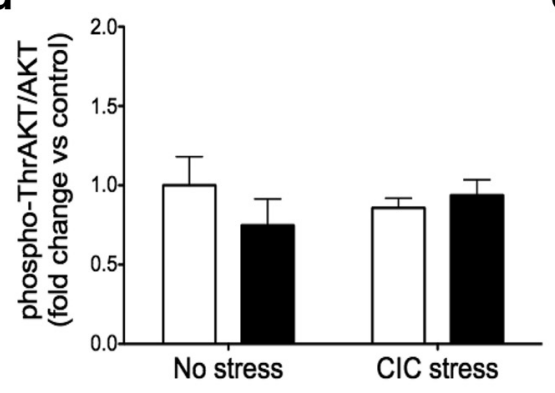

b

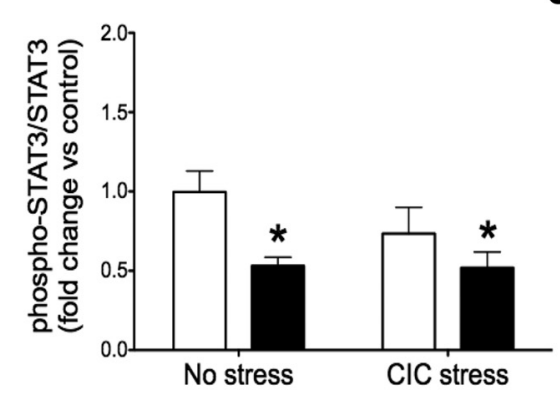

e

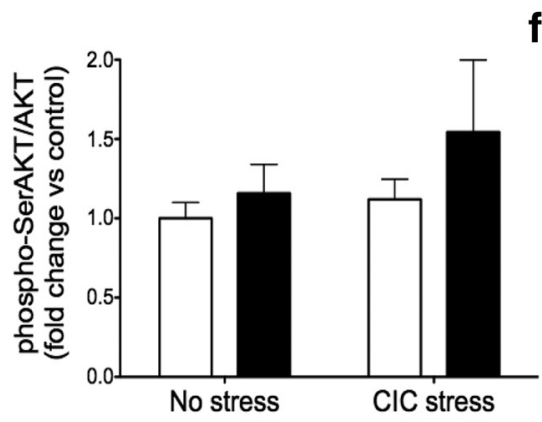

C

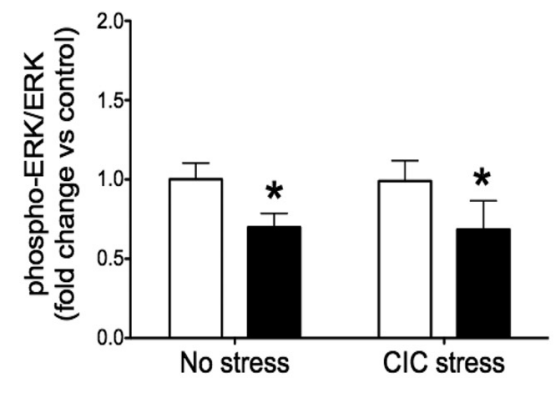

\begin{tabular}{lllll} 
& $\mathrm{NS} \quad \mathrm{NS} \quad \mathrm{ClC}$ \\
\hline
\end{tabular}

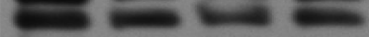

STAT3

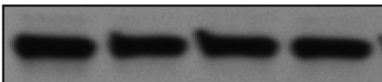

phospho-ERK1/2

(Thr202/Tyr204)

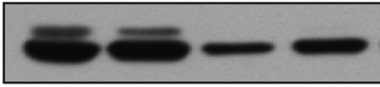

ERK1/2
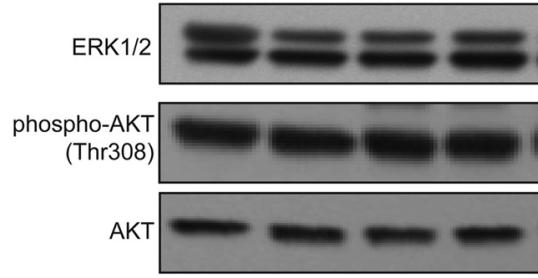

phospho-AKT

(Ser473)

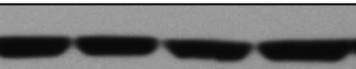

AKT

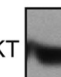

Figure 1. Effect of central IL-6 immunoneutralization on reversal learning and downstream signaling pathways in the OFC. $a$, Both CIC stress and treatment with an anti-IL-6 antibody (200 ng/d, i.c.v.) increased trials to meet criterion on the reversal learning stage of the attentional set-shifting test. ${ }^{*} p<0.05$, main effect compared with IgG control groups. ${ }^{+} p<0.05$, main effect compared with nonstress control groups. $\boldsymbol{b}-\boldsymbol{e}$, Treatment with the IL-6 antibody decreased STAT3 and ERK1/2 phosphorylation in the OFC without affecting AKT phosphorylation. Fold change relative to No Stress, IgG Antibody control group. ${ }^{*} p<0.05$, main effect compared with IgG control groups. $f$, Representative Western blot images. $n=9-11$ per group.

phosphorylation (Fig. $\left.1 c ; F_{(1,32)}=5.996, p=0.02\right)$, but no effects on AKT phosphorylation at either the Thr308 (Fig. 1d) or the Ser473 phosphorylation sites (Fig. 1e). Representative Western blot images are shown in Figure 1 . Thus, contrary to our original hypothesis, these results suggest that basal IL-6 signaling, acting potentially through the JAK/STAT or ERK1/2 pathways, facilitates reversal learning capability under both stressed and nonstressed conditions.

Experiment 2: acute IL-6 inhibition in the OFC, but not the dorsal striatum, causes a reversal learning deficit

After demonstrating that basal IL-6 facilitates reversal learning, we next wanted to identify the brain region responsible for this effect. The neutralizing anti-IL-6 antibody was injected bilaterally, directly into the OFC immediately before the reversal learning stage of the test. As a control to establish anatomical specificity, another group of rats was injected in the dorsal striatum. Representative examples of bilateral guide cannula tracks localized to the OFC and dorsal striatum are shown in Figures $2 a$ and $2 c$, respectively. Injection of the anti-IL-6 antibody into the OFC impaired reversal learning performance, increasing trials to meet criterion on the reversal learning task compared with the IgG control group (Fig. $2 b ; t_{(11)}=3.309, p=0.007$ ). By contrast, the
anti-IL-6 antibody injection into the dorsal striatum had no effect on reversal learning (Fig. 2d). Together with the results from Experiment 1, this suggests that basal IL-6 signaling facilitates reversal learning specifically in the OFC.

Experiment 3: chronic IL-6 overexpression in the OFC attenuates the reversal learning deficit caused by CIC stress The demonstration that IL-6 immunoneutralization impaired reversal learning in both stressed and nonstressed conditions raised the possibility that elevating IL- 6 in the OFC might improve cognitive performance that has been compromised by chronic stress. Thus, we used AAV vector-mediated gene delivery to increase human IL-6 expression in the OFC and found that the vector-mediated IL- 6 expression attenuated the reversal learning deficit caused by CIC stress. There was a significant main effect of CIC stress and a significant interaction between stress and IL- 6 overexpression (Fig. $3 a$; stress: $F_{(1,24)}=6.857, p=0.0151$; interaction: $F_{(1,24)}=4.742, p=$ $0.0395)$. Post hoc analysis indicated that increasing IL-6 expression in the OFC by AAV-IL-6 had no effect on reversal learning in unstressed animals, but there was a significant improvement in reversal learning performance of CIC- 
a

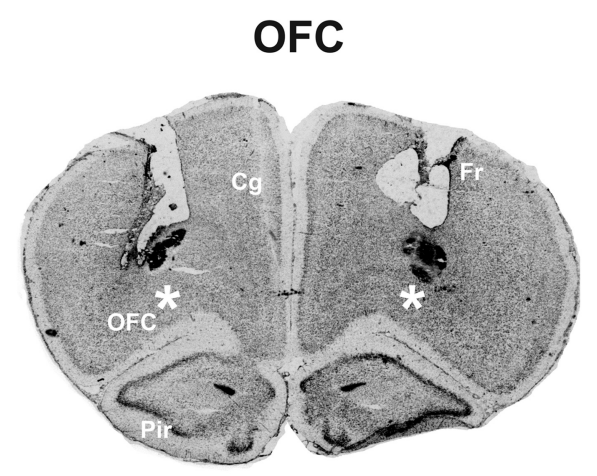

C

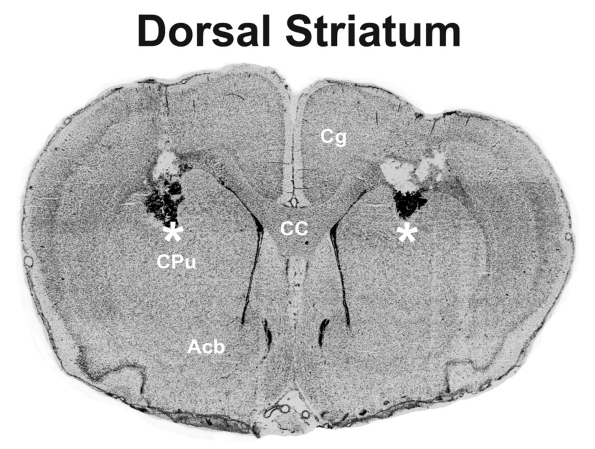

b

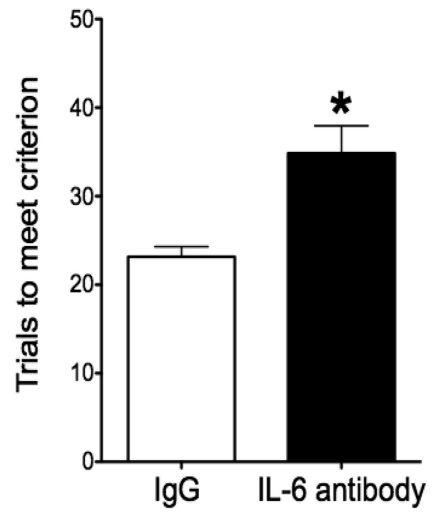

d

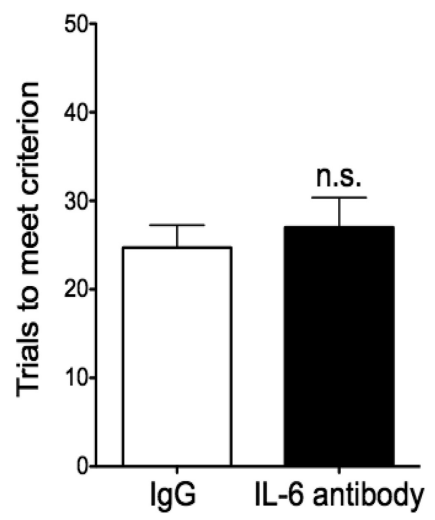

Figure 2. Effect of local IL-6 immunoneutralization on reversal learning performance. $\boldsymbol{a}, \boldsymbol{c}$, Representative images of cannula placement and injection sites in the OFC and dorsal striatum, respectively. *Injection site. $\boldsymbol{b}$, Injection of the anti-IL- 6 antibody into the $\mathrm{OFC}$ increased trials to meet criterion on the reversal learning stage of the attentional set-shifting test compared with the lgG control group. ${ }^{*} p<0.05$, compared with Ig $G$ control group. $\boldsymbol{d}$, Injection of the anti-IL-6 antibody into the dorsal striatum had no effect on reversal learning performance. n.s., Not significantly different from lgG control; $\mathrm{Cg}$, cingulate cortex; Fr, frontal cortex; Pir, piriform cortex; $C C$, corpus collosum; $C P u$, caudate-putamen; $A c b$, nucleus accumbens. $n=6$ or 7 per group.

stressed rats treated with AAV-IL-6 compared with AAVGFP-treated controls after CIC stress (Fig. $3 a$ ).

To determine which cell types were infected by the viral vector, we used dual fluorescence immunohistochemistry to label GFP together with one of three cell-type markers: NeuN for neurons, GFAP for astrocytes, or CD11b for microglia. We found that GFP colocalized with NeuN, but not GFAP or CD11b, suggesting that the viral vector (AAV5 serotype) exclusively infected neurons in the OFC (Fig. 3b). Although all GFP-positive cells expressed NeuN, not all NeuN positive cells expressed GFP, suggesting that only a subpopulation of neurons were infected. At the site of injection, $\sim 40 \%$ of neurons expressed GFP. The spread of infection can be seen in Figure $3 c$. The bulk of infection was located in the OFC, between bregma 3.7 and bregma 2.7. However, a few GFP-positive cells were seen as far anterior as bregma 4.2 and as far posterior as bregma 1.2.

To confirm the effectiveness of viral-mediated gene transfer, OFC tissue was collected after testing on the AST for analysis by ELISA and Western blot. The AAV-IL-6 vector increased human IL- 6 protein levels in the OFC in both stressed and unstressed rats (Fig. $3 d ; F_{(1,24)}=13.73, p=0.001$ ) without affecting endogenous rat IL-6 expression (Fig. 3e). Human IL-6 has been shown to signal through the rat IL-6 receptor (Hoekzema et al., 1991). To confirm that our overexpression system had functional consequences and to identify the signaling pathways involved, we measured STAT3, ERK1/2, and AKT phosphorylation in the OFC by Western blot. IL-6 overexpression activated the JAK/STAT pathway in the OFC without affecting ERK1/2 or AKT. Specifically, there was a significant main effect of IL-6 overexpression on STAT3 phosphorylation (Fig. $3 f ; F_{(1,24)}=43.75, p<0.0001$ ), but no significant effects on ERK1/2 (Fig. $3 g$ ) or AKT phosphorylation (Fig. 3h,i). Representative Western blot images are shown in Figure 3j. These results suggest that IL-6, expressed and presumably secreted specifically by neurons in the OFC, attenuates the detrimental effect of CIC stress on reversal learning, associated with activation of the JAK/STAT signaling pathway.

Experiment 4: acute IL-6
administration into the $\mathrm{O}$. administration into the $\mathrm{OFC}$ restores reversal learning performance that has been disrupted by CIC stress

In the next experiment, we confirmed and extended the findings of Experiment 3 by demonstrating that an acute administration of exogenous IL- 6 into the OFC at the time of testing was sufficient to reverse the CIC stress-induced deficit in cognitive function. There was a significant main effect of CIC stress and a significant stress $\times$ drug interaction (Fig. 4; stress: $F_{(1,30)}=6.904, p=0.0134$; interaction: $\left.F_{(1,30)}=5.685, p=0.0236\right)$. Post hoc analysis shows that IL-6 administration had no effect in nonstressed animals, but CICstressed rats that received IL-6 required significantly fewer trials to meet criterion compared with those injected with vehicle. Together, these results suggest that increasing IL- 6 in the OFC at the time of testing is sufficient to restore reversal learning capability that was compromised by chronic stress.

\section{Experiment 5: inhibition of the JAK/STAT pathway in the OFC impairs reversal learning}

The Western blot results from Experiments 1 and 3 suggested that IL-6 may act through the JAK/STAT pathway to facilitate reversal learning. To test this hypothesis, we microinjected a specific JAK/ STAT inhibitor, JSI-124, into the OFC before testing reversal learning (Fig. 5). Similar to IL-6 immunoneutralization, JAK/STAT inhibition in the OFC impaired cognitive flexibility. There was a significant effect of JSI-124 administration on trials to meet criterion in the reversal learning stage of the AST (one-way ANOVA: $F_{(2,15)}=$ 13.69, $p=0.0004$ ). Post hoc analysis suggested that the effect of JSI-124 was dose-dependent, as only rats receiving the highest dose were significantly different from vehicle controls. These results, together with those of the preceding experiments, support the hypothesis that IL-6-induced activation of the JAK/STAT pathway facilitates cognitive flexibility in the OFC.

\section{Experiment 6: cellular localization of IL-6 and JAK/STAT}

To determine which cell types in OFC express endogenous IL-6 under noninflammatory conditions, naive animals were used for 
a

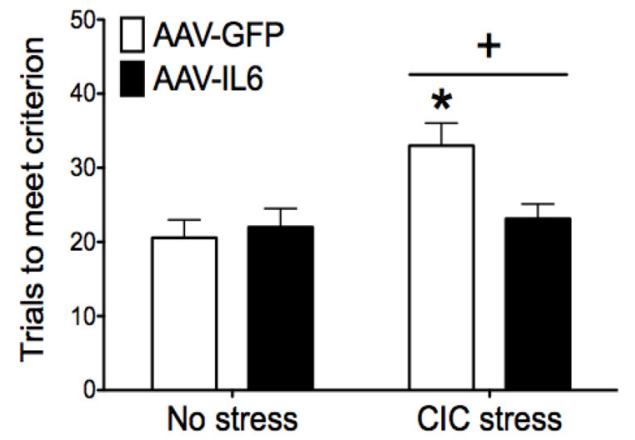

b
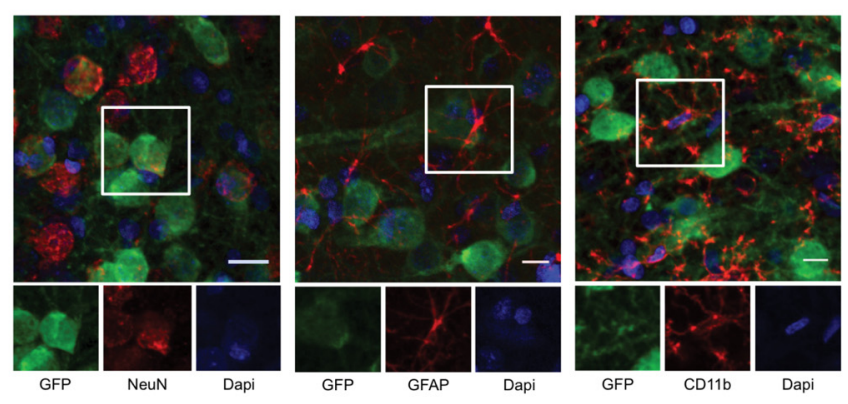

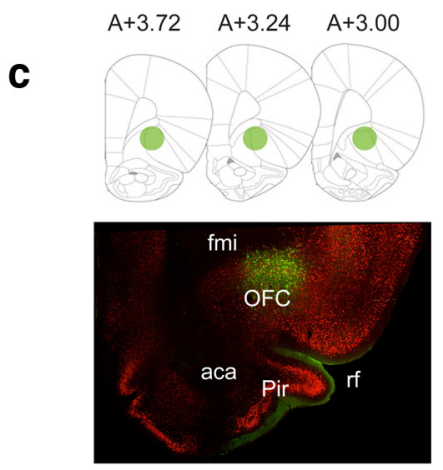

d

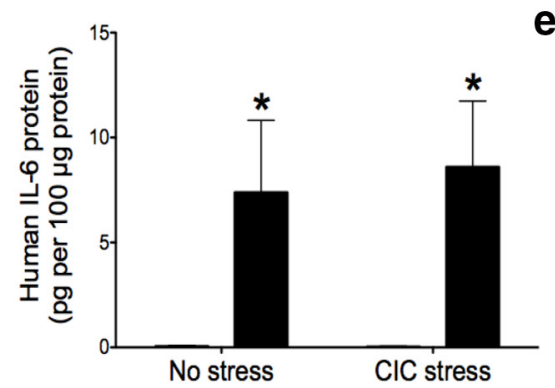

$\mathbf{g}$

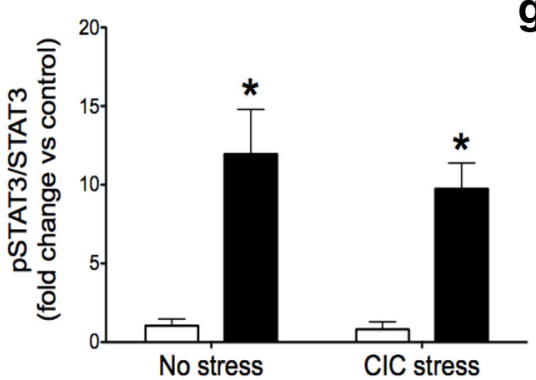

h

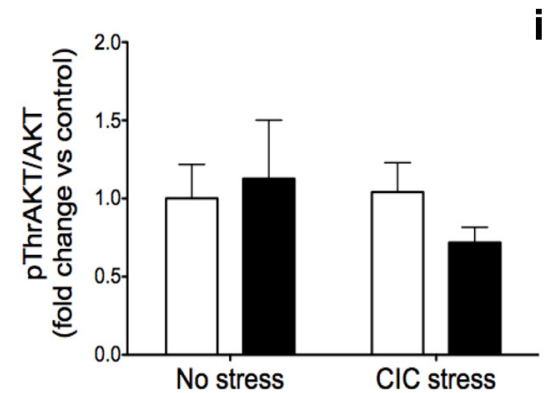

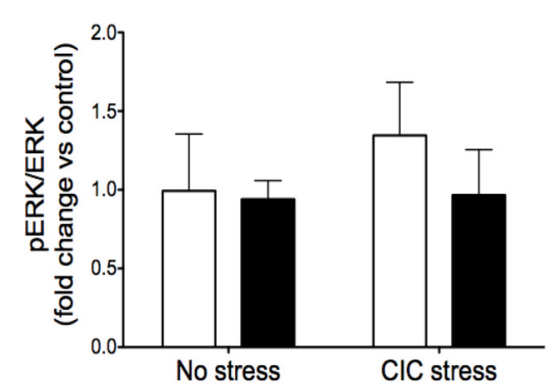

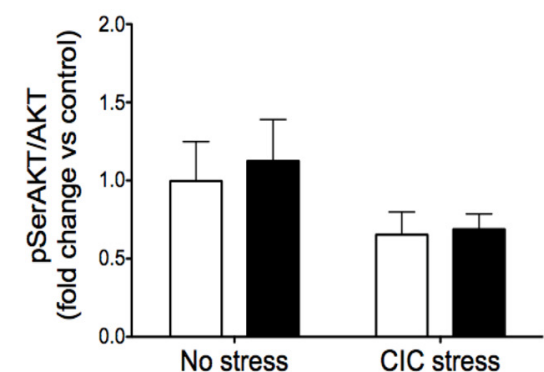

e
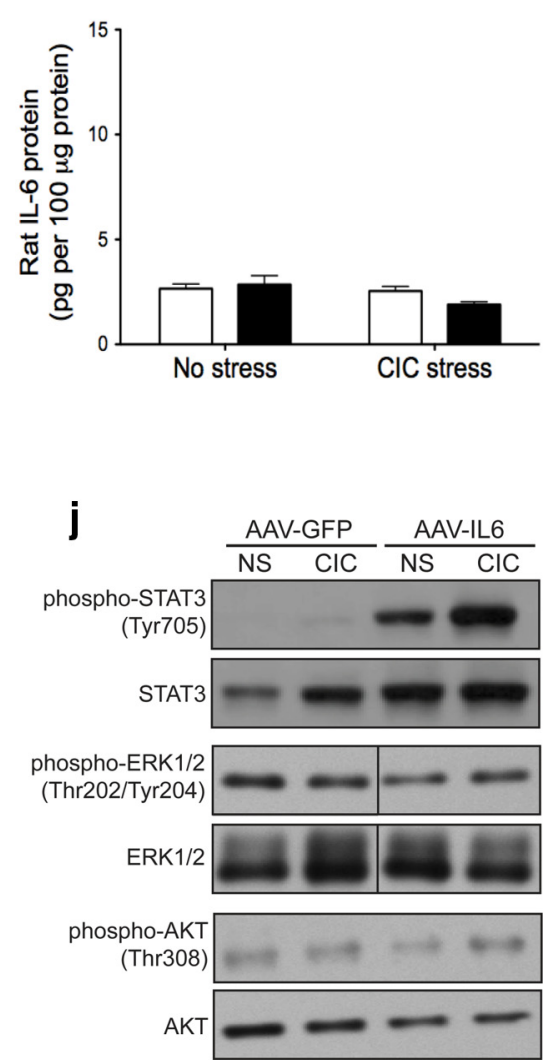

phospho-AKT

(Ser473)

AK

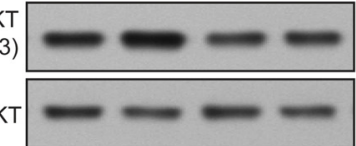

Figure 3. Effect of chronic IL-6 overexpression on reversal learning and downstream signaling pathways in the $0 \mathrm{FC}$. $a$, CIC stress increased trials to meet criterion on the reversal learning task, and AAV-IL-6 injection into the OFC restored reversal learning performance to nonstress levels. ${ }^{+} p<0.05$, main effect compared with no stress control groups. ${ }^{*} p<0.05$, compared with the AAV-IL-6-injected animals subjected to CIC stress. $\boldsymbol{b}$, AAV-GFP exclusively infected neurons, determined by GFP expression seen in neurons but not astrocytes or microglia. Scale bar, $10 \mu \mathrm{m}$. $\boldsymbol{c}$, Representative micrograph showing the extent of infection in the OFC, with corresponding diagrams at AP levels from bregma 3.72 to 3.00 (Paxinos and Watson, 2006). Green represents GFP; red represents NeuN. $\boldsymbol{d}, \boldsymbol{e}$, AAV-IL- 6 increased the expression of recombinant human IL- 6 in the OFC, without affecting endogenous rat IL- 6 levels. ${ }^{*} p<0.05$, main effect compared with AAV-GFPinfected animals. $f-i$, AAV-IL-6 injection increased STAT3 phosphorylation in the OFC without affecting ERK1/2 or AKT phosphorylation. Fold change relative to No Stress, AAV-GFP control group. ${ }^{*} p<0.05$, main effect compared with AAV-GFP-injected animals. $j$, Representative Western blot images. fmi, Forceps minor of the corpus callosum; rf, rhinal fissure; aca, anterior commissure; Pir, piriform cortex. $n=7$ or 8 per group. 


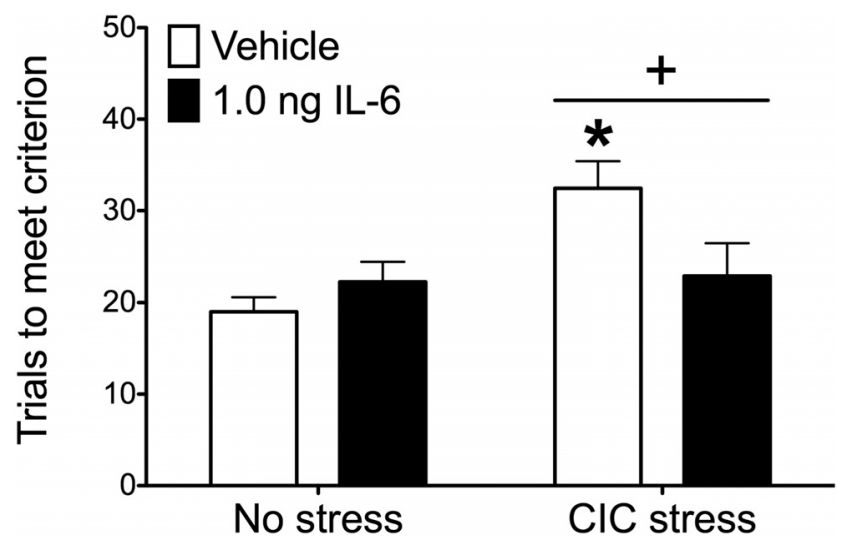

Figure 4. Effect of acute IL-6 injection on reversal learning. CIC stress increased trials to criterion on the reversal learning stage of the attentional set-shifting test, and an acute microinjection of IL-6 $(1.0 \mathrm{ng})$ into the OFC returned performance to nonstress control levels. ${ }^{+} p<$ 0.05 , main effect of $\mathrm{CIC}$ stress compared with nonstress controls. ${ }^{*} p<0.05$ vehicle compared with IL-6 injections in animals subjected to CIC stress. $n=8$ or 9 per group.

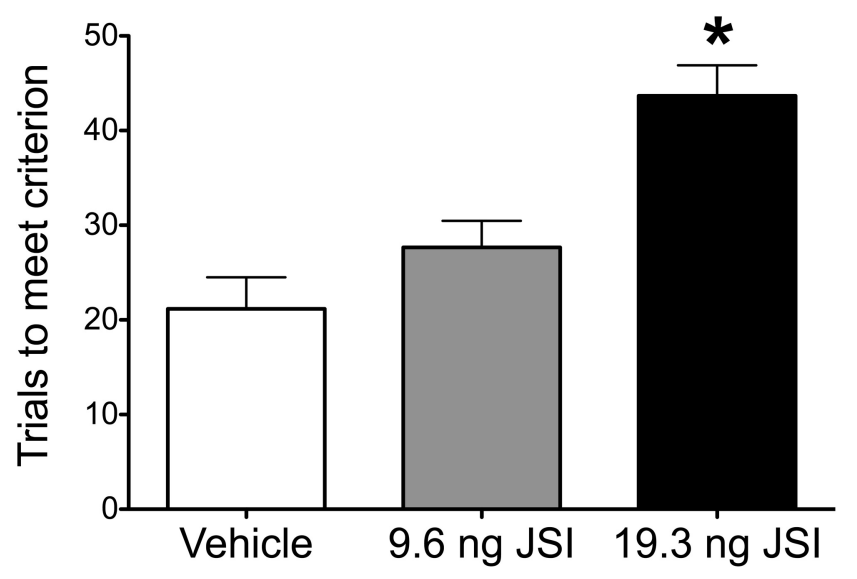

Figure 5. Effect of JAK/STAT pathway inhibition on reversal learning performance. Microinjection of the JAK/STAT inhibitor, JSI-124, into the OFC dose-dependently increased trials to criterion on the reversal learning task. ${ }^{*} p<0.05$, compared with vehicle-injected animals. $n=$ 6 per group.

dual-fluorescence immunohistochemistry to label IL-6 and the cell markers NeuN, GFAP, or CD11b. Representative images are shown in Figure $6 a-c$. Under basal conditions, IL-6 was expressed by both neurons and astrocytes, but not by microglia. Approximately 75\% of the IL-6-positive cells were neuronal, also expressing NeuN. A much smaller proportion of IL-6-positive cells $(\sim 10 \%)$ were astrocytes, also expressing GFAP. Although the majority of IL-6-positive cells were neurons, only a subpopulation of all NeuN-labeled neurons in the OFC expressed IL-6 $(\sim 15 \%)$.

By contrast, all three cell types examined exhibited STAT3 phosphorylation after chronic IL-6 overexpression in rats infected with the AAV-IL-6 virus in the OFC (Fig. $6 d-f$ ). The largest proportion of phospho-STAT3-positive cells were neurons $(\sim 40 \%)$. Astrocytes and microglia made a smaller contribution, $\sim 30 \%$ and $15 \%$, respectively, of phospho-STAT3-positive cells. These results suggest that under basal, noninflammatory conditions, IL-6 is expressed and presumably secreted primarily by neurons, and potentially activates JAK/STAT signaling in neurons and astrocytes and, to a lesser extent, microglia. Thus, basal IL-6 and JAK/STAT signaling in the OFC appears to involve primarily nonimmune cells.

\section{Discussion}

Much of the current research on the role of cytokines in higherorder brain function is based on the hypothesis that the activity of proinflammatory cytokines, driven to high levels in the brain by immune activation and inflammation, has detrimental consequences. However, it is becoming increasingly clear that both proinflammatory and anti-inflammatory cytokines are present in the brain under nonpathological, noninflammatory conditions and that these molecules may play an important role in regulating normal physiological processes. In the current studies, we identified a novel role for the proinflammatory cytokine IL-6 in facilitating reversal learning, a form of cognitive flexibility that is often impaired in psychiatric disease. We found that neutralizing IL- 6 in the brain impaired reversal learning in both stressed and nonstressed animals. This effect was localized specifically to the OFC, as acute microinjections of the IL- 6 antibody directly into the OFC also impaired reversal learning, whereas injections into the dorsal striatum had no effect. We showed that, under basal conditions, IL-6 expression, as well as JAK/STAT activation after chronic IL-6 overexpression, occurred primarily in neurons and, to a lesser extent, in astrocytes, but not in microglia, the resident immune cells of the brain. We further showed that inhibiting the JAK/STAT signaling pathway, a downstream mediator of IL-6 activity, also compromised reversal learning, providing convergent evidence for a role of this cytokine signaling system in facilitating cognitive flexibility. These results suggest that, under basal, noninflammatory conditions, IL-6 and JAK/STAT signaling in the OFC facilitate reversal learning.

We have established previously that CIC stress impairs reversal learning and that this effect can be prevented or reversed by chronic antidepressant treatment (Danet et al., 2010), providing a model for the cognitive inflexibility seen in stress-related psychiatric diseases, such as depression. In the current studies, we also demonstrated that elevating IL- 6 in the OFC, either chronically throughout the stress treatment by local infection with IL6-expressing AAV or acutely by local microinjection at the time of testing, attenuated the cognitive deficit induced by chronic stress. Thus, these results suggest that, although IL-6 may not play a role in the mechanism of stress-induced cognitive pathology, this pathway may represent a novel therapeutic target for treating cognitive dysfunction associated with psychiatric illnesses, perhaps specifically in cases where inflammation is not a prominent factor. Indeed, an important caveat in the present study is that it does not address a potential role for excessively high IL-6 levels in possibly contributing to cognitive dysfunction associated with inflammation.

Although the literature on the effects of cytokines on cognition is not extensive, our results are in line with previous observations that IL-6, like other proinflammatory cytokines, can influence cognition (Yirmiya and Goshen, 2011). Perhaps consistent with its role as both a proinflammatory and anti-inflammatory cytokine, IL-6 has been shown to have both beneficial and detrimental effects on cognition. In one study, exogenous IL-6 administration had no effect in healthy animals (Oitzl et al., 1993), but under inflammatory conditions, such as aging or after immune stimulation, IL-6 impaired hippocampal-dependent learning and memory (Sparkman et al., 2006; Dugan et al., 2009). By contrast, we found in the current studies that chronic IL- 6 neutralization induced a specific deficit in reversal learning and that IL-6 overexpression attenuated the reversal learning deficit caused by chronic stress. Likewise, in another study, endogenous IL-6 or exogenous IL- 6 administered before an insult also facilitated cog- 
nitive function (Matsuda et al., 1996; Baier et al., 2009). Cognitive flexibility and working memory represent distinct, sometimes even opposing, cognitive processes, mediated by different brain circuits. In our experiments, acute IL- 6 was administered immediately before testing on the reversal task, thus avoiding any potential confounding effects on the preceding simple and compound discriminations. However, these earlier stages of the AST were also unaffected by the chronic manipulations, suggesting that IL-6 in the OFC specifically facilitates reversal learning, rather than affecting learning and memory processes in general. Thus, the effects of IL-6 on cognition are complex and may depend on factors, including the specific cognitive task, the brain regions involved, the physiological context, timing and duration of exposure, and IL-6 expression levels.

IL-6 may exert differential effects (i.e., producing deficits when expressed under inflammatory conditions, but facilitating function at basal levels), by activating different signaling pathways and/or cell types. IL-6 can activate three signaling pathways, JAK/STAT, ERK, and PI3K/AKT, allowing for alternative responses (Heinrich et al., 2003). We demonstrated that JAK/STAT signaling facilitates cognitive flexibility, suggesting a beneficial role for this pathway, which is in line with a limited litera-

ture on JAK/STAT signaling in cognition (Chiba et al., 2009; Park et al., 2013). However, JAK/STAT signaling is not unique to IL-6, and it is possible that other molecules that activate this pathway can also influence cognition through JAK/STAT signaling. The different signaling pathways can also regulate each other and interact with other signaling pathways, which may occur particularly when other cytokines are elevated, as occurs in inflammation (Kumar et al., 1997). Further, astrocytes, neurons, and microglia have all been shown to produce and respond to IL-6 (Marz et al., 1998; Jankord et al., 2010), so the cell types involved in IL-6 signaling under different conditions may determine the functional outcome. For example, nontargeted IL- 6 overexpression in the brain increased the number of excitatory synapses and mushroom-shaped spines (Wei et al., 2012), whereas IL-6 expression specifically in astrocytes had detrimental effects on dendritic morphology (Campbell et al., 1993). We found that JAK/ STAT signaling was activated primarily in neurons after IL-6 overexpression, and others have demonstrated that IL-6 acting on neurons can prevent degeneration (Pizzi et al., 2004), promote neurite outgrowth (Schäfer et al., 1999), and attenuate excitotoxic damage (Wang et al., 2009). It is possible that neuronal IL- 6 acts in an autocrine fashion to have beneficial neuroprotective effects, whereas induced IL-6 released by astrocytes or microglia under inflammatory conditions may contribute to a more neurotoxic state.

There are multiple mechanisms by which neuronal IL- 6 could facilitate cognitive flexibility under basal conditions, including its ability to interact with neurotransmitters, to influence plasticity, and to regulate neuronal excitability. Reversal learning is facili- b

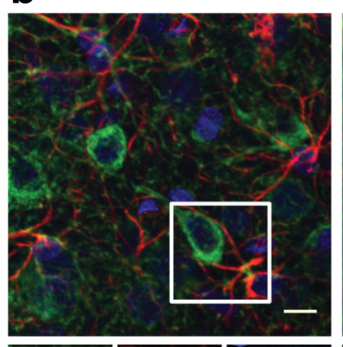

C
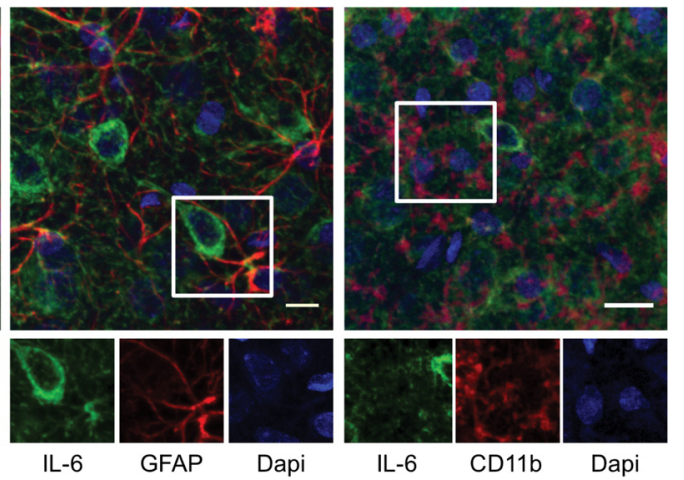

e

f

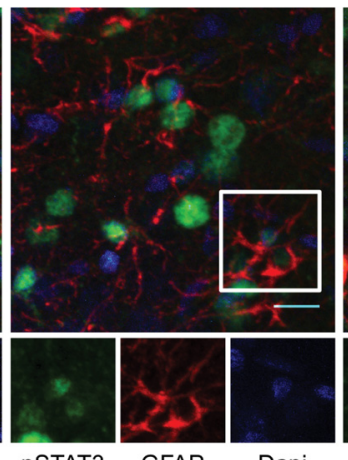

pSTAT3

Dapi

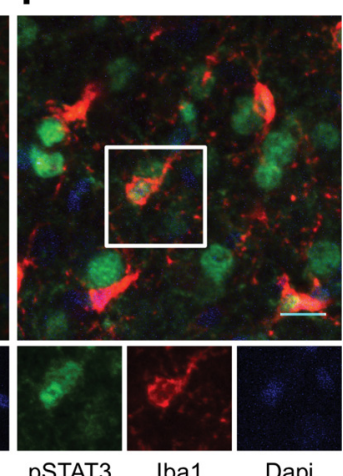

pSTAT3 Iba1 Dapi

GFAP

api

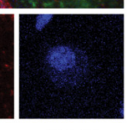

Dap

Figure 6. Basal IL-6 expression and IL-6 induced STAT3 phosphorylation in the OFC. $\boldsymbol{a}$, The majority of IL-6-positive cells in the FC also expressed the neuronal marker, NeuN. $\boldsymbol{b}$, A smaller percentage of IL-6-positive cells also expressed the astrocytic marker, Iso expressed the neuronal marker, NeuN. e, In addition, astrocytes labeled with GFAP expressed phospho-STAT3.f, A very small were observed to express phospho-STAT3 in the OFC. Scale bar, $10 \mu \mathrm{m} . n=3$ per group.

tated by serotonin, a modulatory neurotransmitter targeted in the treatment of mood and anxiety disorders. Serotonin signaling in the OFC is required for optimal reversal learning, an effect mediated in part by cortical serotonin-2A receptors (Danet et al., 2010; Furr et al., 2012). IL-6 may interact with this neurotransmitter system (e.g., influencing the mechanisms involved in serotonin release, signaling, or metabolism). Further, the JAK/ STAT pathway may be a point of convergence for IL-6 and serotonin signaling, as the serotonin-2A receptor has been shown to couple to JAK/STAT in muscle tissue (Guillet-Deniau et al., 1997). Alternatively, IL-6 and JAK/STAT signaling may both influence reversal learning by regulating neuronal plasticity. IL-6 is released during long-term potentiation (Balschun et al., 2004), a cellular correlate of learning and memory, and can influence dendritic and spine morphology (Wei et al., 2012), disruptions of which have been associated with psychiatric illness, and with deficits of cognitive flexibility in animal models (Liston et al., 2006; Penzes et al., 2011). The JAK/STAT pathway may also be involved in synaptic plasticity. In addition to genomic effects, STAT proteins have been shown to influence microtubule stability (Ng et al., 2006) and are localized to the postsynaptic density where they regulate NMDA-mediated synaptic plasticity (Nicolas et al., 2012). Finally, the effects of IL-6 and JAK/STAT signaling on reversal learning may result from the modulation of neuronal excitability. Prefrontal cortical regions are hypoactive in depression and other psychiatric disorders associated with executive dysfunction (Drevets, 2007), and IL-6 can enhance cortical excitability (Garcia-Oscos et al., 2012). Interestingly, this may explain how low levels of IL- 6 facilitate cognitive function whereas higher 
levels, which could potentially induce excitotoxicity, can be detrimental.

Executive dysfunction and associated changes in prefrontal cortical activity are increasingly recognized as an important component of many psychiatric diseases. The mechanisms by which this dysfunction occurs remain to be elucidated, and current treatment strategies often fail to resolve the cognitive components of such illness (Williams et al., 2000). In the current studies, we investigated the role of IL-6 and its downstream JAK/STAT signaling pathway in cognitive function in the OFC. We demonstrated that basal IL-6 and JAK/STAT signaling facilitates a translationally relevant form of cognitive flexibility. Some investigators have proposed that anti-inflammatory drugs may be beneficial for the treatment of psychiatric illness (Dantzer et al., 2008). However, our results would suggest that caution is warranted, that a reduction in immune signaling may not be universally effective, and as shown by others, could even exacerbate aspects of the disorder or attenuate therapeutic efficacy under certain conditions (Warner-Schmidt et al., 2011). Indeed, our data would suggest that, in cases where inflammation is not prominent, elevating IL-6 and/or JAK2-STAT3 signaling may improve executive function, which may alleviate other symptoms and ultimately contribute to a more effective treatment response.

\section{References}

Baier PC, May U, Scheller J, Rose-John S, Schiffelholz T (2009) Impaired hippocampus-dependent and -independent learning in IL-6 deficient mice. Behav Brain Res 200:192-196. CrossRef Medline

Balschun D, Wetzel W, Del Rey A, Pitossi F, Schneider H, Zuschratter W, Besedovsky HO (2004) Interleukin-6: a cytokine to forget. FASEB J 18: 1788-1790. CrossRef Medline

Braida D, Sacerdote P, Panerai AE, Bianchi M, Aloisi AM, Iosuè S, Sala M (2004) Cognitive function in young and adult IL (interleukin)-6 deficient mice. Behav Brain Res 153:423-429. CrossRef Medline

Burger C, Gorbatyuk OS, Velardo MJ, Peden CS, Williams P, Zolotukhin S, Reier PJ, Mandel RJ, Muzyczka N (2004) Recombinant AAV viral vectors pseudotyped with viral capsids from serotypes 1,2, and 5 display differential efficiency and cell tropism after delivery to different regions of the central nervous system. Mol Ther 10:302-317. CrossRef Medline

Campbell IL, Abraham CR, Masliah E, Kemper P, Inglis JD, Oldstone MB, Mucke L (1993) Neurologic disease induced in transgenic mice by cerebral overexpression of interleukin 6. Proc Natl Acad Sci U S A 90:1006110065. CrossRef Medline

Chiba T, Yamada M, Sasabe J, Terashita K, Shimoda M, Matsuoka M, Aiso S (2009) Amyloid- $\beta$ causes memory impairment by disturbing the JAK2/ STAT3 axis in hippocampal neurons. Mol Psychiatry 14:206-222. CrossRef Medline

Clarke HF, Dalley JW, Crofts HS, Robbins TW, Roberts AC (2004) Cognitive inflexibility after prefrontal serotonin depletion. Science 304:878880. CrossRef Medline

Clarke HF, Robbins TW, Roberts AC (2008) Lesions of the medial striatum in monkeys produce perseverative impairments during reversal learning similar to those produced by lesions of the orbitofrontal cortex. J Neurosci 28:10972-10982. CrossRef Medline

Danet M, Lapiz-Bluhm S, Morilak DA (2010) A cognitive deficit induced in rats by chronic intermittent cold stress is reversed by chronic antidepressant treatment. Int J Neuropsychopharmacol 13:997-1009. CrossRef Medline

Dantzer R, O'Connor JC, Freund GG, Johnson RW, Kelley KW (2008) From inflammation to sickness and depression: when the immune system subjugates the brain. Nat Rev Neurosci 9:46-56. CrossRef Medline

De Steno DA, Schmauss C (2009) A role for dopamine D2 receptors in reversal learning. Neuroscience 162:118-127. CrossRef Medline

Drevets WC (2007) Orbitofrontal cortex function and structure in depression. Ann N Y Acad Sci 1121:499-527. CrossRef Medline

Dugan LL, Ali SS, Shekhtman G, Roberts AJ, Lucero J, Quick KL, Behrens MM (2009) IL-6 mediated degeneration of forebrain GABAergic interneurons and cognitive impairment in aged mice through activation of neuronal NADPH Oxidase. PLos One 4:e5518. CrossRef Medline
Furr A, Lapiz-Bluhm MD, Morilak DA (2012) 5-HT2A receptors in the orbitofrontal cortex facilitate reversal learning and contribute to the beneficial cognitive effects of chronic citalopram treatment in rats. Int J Neuropsychopharmacol 15:1295-1305. CrossRef Medline

Garcia-Oscos F, Salgado H, Hall S, Thomas F, Farmer GE, Bermeo J, Galindo LC, Ramirez RD, D’Mello S, Rose-John S, Atzori M (2012) The stressinduced cytokine interleukin- 6 decreases the inhibition/excitation ratio in the rat temporal cortex via trans-signaling. Biol Psychiatry 71:574-582. CrossRef Medline

Gimeno D, Kivimäki M, Brunner EJ, Elovainio M, De Vogli R, Steptoe A, Kumari M, Lowe GD, Rumley A, Marmot MG, Ferrie JE (2009) Associations of C-reactive protein and interleukin- 6 with cognitive symptoms of depression: 12-year follow-up of the Whitehall II study. Psychol Med 39:413-423. CrossRef Medline

Gray SJ, Foti SB, Schwartz JW, Bachaboina L, Taylor-Blake B, Coleman J, Ehlers MD, Zylka MJ, McCown TJ, Samulski RJ (2011) Optimizing promoters for recombinant adeno-associated virus-mediated gene expression in the peripheral and central nervous system using self-complementary vectors. Hum Gene Ther 22:1143-1153. CrossRef Medline

Grieger JC, Choi VW, Samulski RJ (2006) Production and characterization of adeno-associated viral vectors. Nat Protoc 1:1412-1428. CrossRef Medline

Guillet-Deniau I, Burnol AF, Girard J (1997) Identification and localization of a skeletal muscle secrotonin 5-HT2A receptor coupled to the Jak/STAT pathway. J Biol Chem 272:14825-14829. CrossRef Medline

Harting MT, Jimenez F, Adams SD, Mercer DW, Cox CS Jr (2008) Acute, regional inflammatory response after traumatic brain injury: implications for cellular therapy. Surgery 144:803-813. CrossRef Medline

Heinrich PC, Behrmann I, Haan S, Hermanns HM, Muller-Newen G, Schaper F (2003) Principles of interleukin (IL)-6-type cytokine signalling and its regulation. Biochem J 372:1-20. CrossRef Medline

Hoekzema R, Murray PI, van Haren MA, Helle M, Kijlstra A (1991) Analysis of interleukin-6 in endotoxin-induced uveitis. Invest Ophthalmol Vis Sci 32:88-95. Medline

Jankord R, Zhang R, Flak JN, Solomon MB, Albertz J, Herman JP (2010) Stress activation of IL-6 neurons in the hypothalamus. Am J Physiol Regul Integr Comp Physiol 299:R343-R351. CrossRef Medline

Johnson JS, Li C, DiPrimio N, Weinberg MS, McCown TJ, Samulski RJ (2010) Mutagenesis of adeno-associated virus type 2 capsid protein VP1 uncovers new roles for basic amino acids in trafficking and cell-specific transduction. J Virol 84:8888-8902. CrossRef Medline

Kumar A, Commane M, Flickinger TW, Horvath CM, Stark GR (1997) Defective TNF- $\alpha$-induced apoptosis in STAT1-null cells due to low constitutive levels of caspases. Science 278:1630-1632. CrossRef Medline

Lapiz-Bluhm MD, Soto-Piña AE, Hensler JG, Morilak DA (2009) Chronic intermittent cold stress and serotonin depletion induce deficits of reversal learning in an attentional set-shifting test in rats. Psychopharmacology 202:329-341. CrossRef Medline

Lee B, Groman S, London ED, Jentsch JD (2007) Dopamine D2//D3 receptors play a specific role in the reversal of a learned visual discrimination in monkeys. Neuropsychopharmacology 32:2125-2134. CrossRef Medline

Leeson VC, Robbins TW, Matheson E, Hutton SB, Ron MA, Barnes TR, Joyce EM (2009) Discrimination learning, reversal, and set-shifting in firstepisode schizophrenia: stability over six years and specific associations with medication type and disorganization syndrome. Biol Psychiatry 66: 586-593. CrossRef Medline

Liston C, Miller MM, Goldwater DS, Radley JJ, Rocher AB, Hof PR, Morrison JH, McEwen BS (2006) Stress-induced alterations in prefrontal cortical dendritic morphology predict selective impairments in perceptual attentional set-shifting. J Neurosci 26:7870-7874. CrossRef Medline

Marz P, Cheng JG, Gadient RA, Patterson PH, Stoyan T, Otten U, Rose-John S (1998) Sympathetic neurons can produce and respond to interleukin 6. Proc Natl Acad Sci U S A 95:3251-3256. CrossRef Medline

Matsuda S, Wen TC, Morita F, Otsuka H, Igase K, Yoshimura H, Sakanaka M (1996) Interleukin-6 prevents ischemia-induced learning disability and neuronal and synaptic loss in gerbils. Neurosci Lett 204:109-112. CrossRef Medline

Must A, Szabó Z, Bódi N, Szász A, Janka Z, Kéri S (2006) Sensitivity to reward and punishment and the prefrontal cortex in major depression. J Affect Disord 90:209-215. CrossRef Medline

Ng DC, Lin BH, Lim CP, Huang G, Zhang T, Poli V, Cao X (2006) Stat3 
regulates microtubules by antagonizing the depolymerization activity of stathmin. J Cell Biol 172:245-257. CrossRef Medline

Nicolas CS, Peineau S, Amici M, Csaba Z, Fafouri A, Javalet C, Collett VJ, Hildebrandt L, Seaton G, Choi SL, Sim SE, Bradley C, Lee K, Zhuo M, Kaang BK, Gressens P, Dournaud P, Fitzjohn SM, Bortolotto ZA, Cho K, et al. (2012) The JAK/STAT pathway is involved in synaptic plasticity. Neuron 73:374-390. CrossRef Medline

Oitzl MS, van Oers H, Schöbitz B, de Kloet ER (1993) Interleukin-1 $\beta$, but not interleukin-6, impairs spatial navigation learning. Brain Res 613:160163. CrossRef Medline

Palin K, Moreau ML, Sauvant J, Orcel H, Nadjar A, Duvoid-Guillou A, Dudit J, Rabié A, Moos F (2009) Interleukin-6 activates arginine vasopressin neurons in the supraoptic nucleus during immune challenge in rats. Am J Physiol Endocrinol Metab 296:E1289-E1299. CrossRef Medline

Park SJ, Shin EJ, Min SS, An J, Li Z, Hee Chung Y, Hoon Jeong J, Bach JH, Nah SY, Kim WK, Jang CG, Kim YS, Nabeshima Y, Nabeshima T, Kim HC (2013) Inactivation of JAK2/STAT3 signaling axis and downregulation of M1 mAChR cause cognitive impairment in klotho mutant mice, a genetic model of aging. Neuropsychopharmacology 38:1426-1437. CrossRef Medline

Paxinos G, Watson C (2006) The rat brain in stereotaxic coordinates, Ed 6. London: Elsevier.

Penzes P, Cahill ME, Jones KA, VanLeeuwen JE, Woolfrey KM (2011) Dendritic spine pathology in neuropsychiatric disorders. Nat Neurosci 14: 285-293. CrossRef Medline

Peppard JV, Orlans E (1980) The biological half-lives of four rats immunoglobulin isotypes. Immunology 40:683-686. Medline

Pizzi M, Sarnico I, Boroni F, Benarese M, Dreano M, Garotta G, Valerio A, Spano P (2004) Prevention of neuron and oligodendrocyte degeneration by interleukin-6 (IL-6) and IL-6 receptor/IL-6 fusion protein in organotypic hippocampal slices. Mol Cell Neurosci 25:301-311. CrossRef Medline

Remijnse PL, Nielen MM, van Balkom AJ, Cath DC, van Oppen P, Uylings HB, Veltman DJ (2006) Reduced orbitofrontal-striatal activity on a reversal learning task in obsessive-compulsive disorder. Arch Gen Psychiatry 63:1225-1236. CrossRef Medline

Schäfer KH, Mestres P, März P, Rose-John S (1999) The IL-6/sIL-6R fusion protein hyper-IL-6 promotes neurite outgrowth and neuron survival in cultured enteric neurons. J Interferon Cytokine Res 19:527-532. CrossRef Medline

Sparkman NL, Buchanan JB, Heyen JR, Chen J, Beverly JL, Johnson RW (2006) Interleukin-6 facilitates lipopolysaccharide-induced disruption in working memory and expression of other proinflammatory cytokines in hippocampal neuronal cell layers. J Neurosci 26:10709-10716. CrossRef Medline

Steptoe A, Hamer M, Chida Y (2007) The effects of acute psychological stress on circulating inflammatory factors in humans: a review and metaanalysis. Brain Behav Immun 21:901-912. CrossRef Medline

Sun J, Blaskovich MA, Jove R, Livingston SK, Coppola D, Sebti SM (2005) Cucurbitacin Q: a selective STAT3 activation inhibitor with potent antitumor activity. Oncogene 24:3236-3245. CrossRef Medline

Wang XQ, Peng YP, Lu JH, Cao BB, Qiu YH (2009) Neuroprotection of interleukin-6 against NMDA attack and its signal transduction by JAK and MAPK. Neurosci Lett 450:122-126. CrossRef Medline

Warner-Schmidt JL, Vanover KE, Chen EY, Marshall JJ, Greengard P (2011) Antidepressant effects of selective serotonin reuptake inhibitors (SSRIs) are attenuated by antiinflammatory drugs in mice and humans. Proc Natl Acad Sci U S A 108:9262-9267. CrossRef Medline

Weaver JD, Huang MH, Albert M, Harris T, Rowe JW, Seeman TE (2002) Interleukin-6 and risk of cognitive decline: MacArthur Studies of Successful Aging. Neurology 59:371-378. CrossRef Medline

Wei H, Chadman KK, McCloskey DP, Sheikh AM, Malik M, Brown WT, Li X (2012) Brain IL-6 elevation causes neuronal circuitry imbalances and mediates autism-like behaviors. Biochim Biophys Acta 1822:831-842. CrossRef Medline

Williams JW Jr, Mulrow CD, Chiquette E, Noël PH, Aguilar C, Cornell J (2000) A systematic review of newer pharmacotherapies for depression in adults: evidence report summary: clinical guideline, part 2. Ann Intern Med 132:743-756. CrossRef Medline

Wingren AG, Björkdahl O, Labuda T, Björk L, Andersson U, Gullberg U, Hedlund G, Sjögren HO, Kalland T, Widegren B, Dohlsten M (1996) Fusion of a signal sequence to the interleukin- $1 \beta$ gene directs the protein from cytoplasmic accumulation to extracellular release. Cell Immunol 169:226-237. CrossRef Medline

Yirmiya R, Goshen I (2011) Immune modulation of learning, memory, neural plasticity and neurogenesis. Brain Behav Immun 25:181-213. CrossRef Medline 